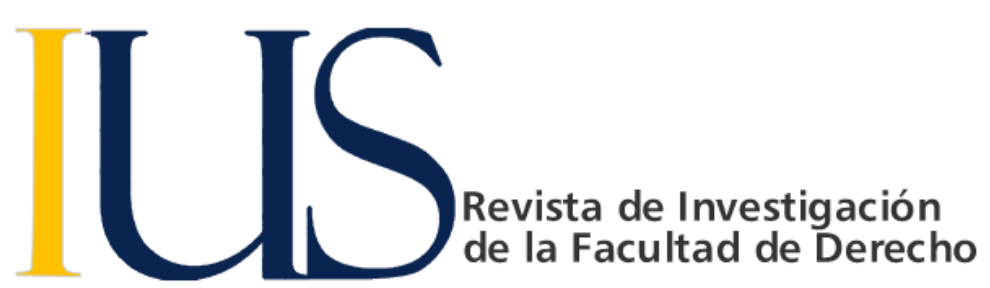

\title{
Sobre el pretendido Reconocimiento Civil a las Uniones Homosexuales
}

\section{Díaz Delgado Tania ${ }^{1}$}

\begin{tabular}{ll}
\hline INFORMACIÓN DEL ARTíCULO & RESUMEN \\
\hline $\begin{array}{l}\text { Historia del artículo: } \\
\text { Recibido el } 10 \text { de mayo de } 2012\end{array}$ & El proyecto de ley № $04181 / 2010-C R$ el mismo que propone establecer las uniones \\
Aceptado el 15 de junio de 2012 & civiles entre personas del mismo sexo, carece de todo sustento fáctico, jurídico, lógico \\
& y racional y no pasa el test de proporcionalidad o razonabilidad, principio orientador \\
\hline Palabras claves: & de todo el sistema jurídico. La pretendida protección legal que se busca con esta ley, \\
Matrimonio & resulta ser una falacia dado que, como se puede verificar, hoy en día estas personas \\
Unión de hecho & haciendo uso de la normatividad vigente, pueden obtener los fines que alegan \\
Homosexualidad & perseguir con dicha ley. Así tenemos que, si de lo que se trata es no dejar desprotegidos \\
& patrimonialmente a la "pareja" en caso de ausencia, desaparición, muerte, separación, \\
& etc. pueden acudir a las normas de la compraventa, copropiedad, sucesión \\
& testamentaria, donación, entre otras.
\end{tabular}

\section{About the alleged Civil Recognition of Homosexual Unions}

\section{Introducción}

En estos últimos tiempos hemos sido testigos de cómo se viene debatiendo en distintos medios de comunicación social llámese prensa escrita, televisiva, radial, etc. así como en diferentes espacios políticos, jurídicos y académicos el tema del pretendido reconocimiento civil y hasta del matrimonio entre personas del mismo sexo.

Siendo esto así, se hace necesario analizar el tema desde el punto de vista eminentemente jurídico dado que como es de conocimiento público hoy en día existe un proyecto de ley presentado con tal fin, pendiente de debate en el Congreso de la República.

En efecto, con fecha dos de Agosto del 2010, los congresistas del grupo parlamentario Partido Aprista peruano Vargas Fernández José Augusto, Mulder Bedoya Claude Maurice, Cenzano Sierralta Alfredo Tomás, Valle Riestra Gonzales Olaechea Javier Maximiliano Alfredo Hipólito, Guevara Trelles Miguel Luis y Rodriguez Zavaleta Elías Nicolás, presentaron el proyecto de ley № 04181/2010-CR el mismo que propone establecer las uniones civiles entre personas del mismo sexo, siendo su estado actual para estudio y dictamen de la Comisión de Justicia y Derechos Humanos del Congreso de la República .

En este contexto, el presente artículo pretende ser un pequeño aporte en el análisis y debate jurídico de este tema que, desde nuestro punto de vista, se pretende politizar.

\section{EL MATRIMONIO Y LAS UNIONES DE HECHO EN LA LEGISLACIÓN PERUANA}

Nuestra norma de mayor jerarquía como es nuestra Constitución Política del Perú establece en su artículo 5 o como requisito fundamental para el reconocimiento del concubinato la unión estable de un varón y una mujer. ${ }^{2}$

Asimismo, nuestra misma carta magna en su artículo 4응 establece que la comunidad y el Estado protegen a la familia

\footnotetext{
1 Profesora del área de Derecho Civil de la Facultad de Derecho de la Universidad Católica Santo Toribio de Mogrovejo -Chiclayo (Perú). Contacto: tdiaz@usat.edu.pe

${ }^{2}$ Artículo $5^{\circ}$.- La unión estable de un varón y una mujer, libres de impedimento matrimonial, que forman un hogar de hecho, da lugar a una comunidad de bienes sujeta al régimen de la sociedad de gananciales en cuanto sea aplicable.
} 
promueven el matrimonio y que reconocen a estos últimos como institutos naturales y fundamentales de la sociedad. ${ }^{3}$ Por otro lado, nuestro Código Civil vigente desde el año 1984, con anterioridad a nuestra actual Constitución Política del Perú que data del año 1993, define al matrimonio como la unión voluntariamente concertada por un varón y una mujer legalmente aptos para ella y establece como condición para el reconocimiento del concubinato que se de la unión de hecho voluntariamente realizada y mantenida por un varón y una mujer libres de impedimento matrimonial. ${ }^{4}$

Comentando el artículo 326 de Código Civil, el constitucionalista Enrique Bernales Ballesteros ${ }^{5}$ señala que para considerar la unión estable de hecho, ésta tiene que ser heterosexual: entre varón y mujer, la pareja tiene que estar libre de impedimento matrimonial y tiene que formar un hogar de hecho.

Agrega que la relación tiene que desarrollarse de tal manera que pueda ser tenida como una para alcanzar finalidades $y$ cumplir deberes semejantes a los del matrimonio.

Esto es, vida en común, fidelidad asistencia, procreación y cuidado común de la descendencia, que son las normas esenciales de los deberes y derechos que nacen del matrimonio, contenidos en los artículos 287 a 294 del Código Civil.

Existen posiciones marcadas en cuanto a la conveniencia o inconveniencia de la incorporación del concubinato al régimen legal. En relación a este punto, Josserand señala lo siguiente: " No sólo sería extremadamente grave que una institución como el concubinato se alzara frente a la unión regular o incluso por encima de ella; no solamente una jurisprudencia que tendiera a ese resultado no se apoyaría en ninguna preparación de orden técnico, sino que todavía ella iría en contra de la voluntad de las partes que han entendido vivir al día y eludir todo estatuto matrimonial, aún imperfecto; impondría la calidad de contratantes a quienes han querido permanecer como terceros."

Comentando esta cita de Josserand y citando a Planiol, Ripert y Rouast, Borda señala que la orientación legislativa en esta materia no debe ser desconocer la existencia de la unión libre sino combatirla. ${ }^{6}$

Por su parte, los codificadores franceses, seguidos por muchos otros, son de la opinión, de que si los concubinos prescinden voluntariamente de la ley y se colocan a sabiendas al margen de las garantías que ella ofrece, ésta deberecíprocamente-despreocuparse de los concubinos.

“En relación a este problema es pertinente hacer mención de una preocupación generalizada: Si en la medida que se legalice el concubinato no se está desestimulando el matrimonio. En realidad, ninguna legislación está (al menos formal y declaradamente) en contra del matrimonio: pero el

\footnotetext{
${ }^{3}$ Art. 4.- La comunidad y el Estado protegen especialmente al niño, al adolescente, a la madre y al anciano en situación de abandono. También protegen a la familia y promueven el matrimonio. Reconocen a estos últimos como institutos naturales y fundamentales de la sociedad. La forma del matrimonio y las causas de separación y de disolución son reguladas por la ley.

${ }^{4}$ Art. 326.- La unión de hecho, voluntariamente realizada y mantenida por un varón y una mujer, libres de impedimento matrimonial, para alcanzar finalidades y cumplir deberes semejantes a los del matrimonio, origina una
}

tipo de garantías que se ofrezca a la unión de hecho y los derechos que de ello se deriven pueden producir aquel efecto indeseable.

Esta es, presumiblemente, la razón de que un sector de la doctrina se incline en el sentido de que la ley debe ocuparse del concubinato pero con miras a su gradual extinción". ${ }^{7}$

Como puede verse, nuestra legislación regula la figura jurídica del concubinato y le brinda ciertos derechos pero exigiendo la concurrencia de requisitos esenciales que permitan alcanzar finalidades y cumplir deberes semejantes a los del matrimonio, siendo esto así ¿cuál es la real finalidad que se persigue al pretender legislar las uniones de hecho entre personas del mismo sexo?, ¿ existe fundamento o razón válida alguna para ello?, más aún si en el proyecto de ley № 04181/2010-CR, que a continuación vamos a analizar, se establece que el régimen legal para las uniones afectivas estables entre personas del mismo sexo ha de ser similar en todo al existente para las uniones de hecho.

La unión afectiva entre personas del mismo sexo, no puede, por obvias razones, equipararse desde ningún punto de vista al concubinato regulado en nuestra legislación. Esto es un imposible jurídico, dado que lo impide su propia naturaleza. Si de lo que se trata, de acuerdo a nuestra Constitución y a nuestras leyes es proteger a la familia y promover el matrimonio, por reconocerse que son institutos naturales y fundamentales de la sociedad, no puede legalizarse ningún tipo de unión homosexual que ningún bien aporta ni a la persona en sí misma ni a la familia ni a la sociedad en general. Los grandes males y vicios que padece hoy nuestra sociedad tienen precisamente su raíz en los hogares disfuncionales, hogares donde la práctica de principios y valores está totalmente ausente. ¿Qué puede esperarse para el presente y futuro de nuestra sociedad si empezamos a ir contra la naturaleza humana y el orden natural de las cosas?

\section{ANÁLISIS DEL PROYECTO DE LEY N 041841/2012-CR}

En la exposición de motivos de este proyecto de ley, que como se ha indicado se encuentra actualmente en la Comisión de Justicia y Derechos Humanos del Congreso de la República, se señala entre otras cosas que supuestamente lo habitual en la vida nacional peruana ha sido la exclusión, discriminación, violencia y el escarnio contra las minorías de orientación homosexuales, que "se lesiona derechos y principios fundamentales del ordenamiento constitucional tales como los de dignidad de las personas y el derecho de igualdad y no discriminación..."

En lo que respecta al tema de exclusión, violencia y escarnio, como puede verificarse en la realidad social, la mayoría de las veces estos actos, repudiables por cierto, se dan entre personas de su mismo entorno amical o familiar por

sociedad de bienes que se sujeta al régimen de sociedad de gananciales, en cuanto le fuere aplicable, siempre que dicha unión haya durado por lo menos dos años continuos.

${ }^{5}$ BENALES BALLESTEROS citado por CORNEJO CHAVEZ, Hugo. Tratado de Derecho de Familia, tercera edición, Jurista Editores EIRL, Perú, 2008, página 543.

${ }^{6}$ CORNEJO CHAVEZ, Hugo. Op. cit. p. 529.

${ }^{7}$ CORNEJO CHAVEZ, Hugo. Op. cit. p. 554. 
conflictos y rencillas de diversa índole sobre todo económica, pasional, etc.

Ahora, pretender afirmar que por el hecho de no reconocerles civilmente sus uniones de hecho se les estaría discriminando es desvirtuar y desnaturalizar la esencia del derecho constitucional a la igualdad ante la ley; pues tal como lo ha establecido en reiterada jurisprudencia el Tribunal Constitucional, podemos concebir a la igualdad como un derecho fundamental destinado a obtener un trato paritario ante hechos, situaciones y relaciones equiparables; en otras palabras, hablamos de un derecho subjetivo a no sufrir discriminación, a no ser tratado de manera dispar respecto de quienes se encuentran en una situación equivalente. A contrario sensu, cabe un tratamiento diferenciado frente a situaciones disímiles, para lo cual se debe acreditar que la referida distinción es objetiva y constitucionalmente razonable. En suma, el derecho a la igualdad, consagrado en la Constitución, no significa que siempre y en todos los casos se debe realizar un trato uniforme. El derecho a la igualdad supone tratar "igual a los que son iguales" y "desigual a los que son desiguales". 8

En 2007, la Sala F de la Cámara Nacional Civil en el caso "Rachid" al rechazar el amparo, expresó: "...Lo que el homosexual no puede por exigencia legal es contraer matrimonio con alguien que sea de su mismo sexo. La igualdad ante la ley no significa que no se deben conceder excepciones o privilegios que excluyan a unos de lo que se otorga en igualdad de condiciones a otros, de donde se sigue que la verdadera igualdad consiste en aplicar la ley a los casos concurrentes según las diferencias (...)La norma que establece que el matrimonio debe celebrarse entre personas de distinto sexo tiene una justificación absolutamente objetiva y razonable, que consiste en el interés del Estado en privilegiar uniones que tienden a continuar la especie, sirven para la procreación y dan base a la familia, por lo tanto el distinto tratamiento es proporcionado con respecto a su finalidad."

Además, debe ser bien entendido que es precisamente el reconocimiento jurídico de su dignidad y complejidad personal, la que funda la razonabilidad de algunas prohibiciones y otros límites legales necesarios para prever en vistas del resguardo de la familia y la sociedad y redimensionar sus desmesuradas pretensiones personales frente a sus posibilidades reales. Esta evidencia funda objetivamente los impedimentos que el derecho de familia les impone y otras prohibiciones que habrá de implementar. ${ }^{9}$ “... ¿̇están injustamente discriminados los homosexuales por el hecho de no poder casarse entre sí? La respuesta más evidente, en un primer nivel argumental, es que no. Una persona homosexual puede contraer matrimonio con las

${ }^{8}$ En el sentido anotado STC Exp. № 0261-2003-AA/TC, fundamentos 3.2 y 3.3.

${ }^{9}$ ARIAS DE RONCHIETTO, Catalina Elsa .El matrimonio un bien jurídico indisponible. Cuestión de resguardo del orden público: La familia matrimonial: Indisponible bien jurídico del varón y la mujer. Pontificia Universidad Católica Argentina-Facultad de Derecho, Argentina, Abril de 2010, p. 16 mismas personas y en las mismas condiciones que una persona heterosexual; es decir, con una mujer ( si es varón) o con un varón ( si es mujer). Sería discriminatorio que al homosexual se le impidiera radicalmente contraer matrimonio, con cualquier persona, por el hecho de ser homosexual. Pero no es así: puede casarse cuando quiera, pero con persona del otro sexo, como todos. Del mismo modo sería discriminatorio que solo a los homosexuales (y no a quienes no lo son) se les impidiera casarse con personas del mismo sexo; pero, en el sistema español derogado (vigente todavía en la inmensa mayoría de los ordenamientos del mundo, incluidos los de nuestra cultura y tradición jurídica) ni unos ni otros (homosexuales o heterosexuales) podían casarse con personas del mismo sexo. Nuevamente, el tratamiento era el que recibía cualquier persona. ${ }^{10}$

Estamos frente a un reclamo de colectivos minoritarios que están enfrascados en una batalla legal por unos supuestos derechos sobre identidad sexual. Se pretende minimizar, bien por ignorancia, (en este caso culpable) o bien por un fanatismo laico, los riesgos para la entera sociedad que estas concesiones traen consigo. Detrás de todo esto hay múltiples intereses y un grave desconocimiento de la naturaleza humana.

No confundamos la verdad del lenguaje que cromosómicamente la naturaleza habla y que marca para siempre a la persona, con inclinaciones sexuales diversas que tienen una explicación antropológica, psicológica, y psiquiátrica y a la que penosamente se asocia, en estos últimos tiempos más, la disfuncionalidad matrimonial. ${ }^{11}$

Se argumenta el hecho de que supuestamente "se produce para las parejas estables del mismo sexo una situación jurídica de ausencia de regulación que los deja en condición muy precaria, lo que atenta contra el mandato constitucional de protección legal..."

Habría que preguntarnos de qué manera esta ley, como lo exponen sus autores, otorga "protección" a las personas homosexuales, si como se puede verificar hoy en día estas personas haciendo uso de la normatividad vigente, pueden obtener los fines que alegan perseguir con dicha ley. Así tenemos que, si de lo que se trata es no dejar desprotegidos patrimonialmente a la "pareja" en caso de ausencia, desaparición, muerte, separación, etc. pueden acudir a las normas de la compraventa, copropiedad, sucesión testamentaria, donación, entre otras.

Para solucionar los aspectos patrimoniales de su relación para el caso de extinción del trato, dos convivientes homosexuales pueden recurrir a otras figuras jurídicas: contratos, acuerdos, legados, ajenos al derecho de familia, a fin de evitar y prever perjuicios económicos.

\footnotetext{
${ }^{10}$ MARTínEZ DE AGUIRRE ALDAZ, Carlos y DE PABLO CONTRERAS, Pedro. Constitución, Derecho al matrimonio y uniones entre personas del mismo sexo. Documentos del instituto de Ciencias para la familia, Universidad de Navarra, Ediciones Rialp, S.A., España, 2007, p. 82.

${ }^{11} \mathrm{Cfr}$. CALIENES BEDOYA, Hugo. Polémicos derechos sobre la identidad sexual, artículo publicado en el Diario La Industria, Chiclayo, 24 de Mayo, 2012, p.A2.
} 
Esta relación de dos personas homosexuales adultas y capaces que se agota en sus interesados no corresponde regularla en el derecho de familia. El trato homosexual y los registros locales de "unión civil" hetero u homosexual, por ejemplo el previsto por la ley 1004 de la ciudad de Buenos Aires, no integran el Derecho de Familia.

Respecto de la doctrina que pretende fundar este trato como forma de familia en la que denominan "homoafectividad", debe recordarse que ésta como ningún otro apego, dependencia, sensación o sentimiento podría ser contemplados como causa suficiente de vínculo jurídico familiar ni responde a la esencia y fines de la reconocida "célula natural y fundamental de la sociedad".

También consideramos que la relación psicofísica homosexual, aunque así lo pretenda o crean sus integrantes, no da lugar al ejercicio de la sexualidad humana integral y propiamente tal. No se trata de un límite discriminatorio injusto, es decir, arbitrario, sino fundado en la realidad objetiva.

El trato homosexual carece de la fecundidad psicofísica de la relación matrimonial, en su doble aspecto: respecto de los hijos que procrean, sostienen y educan, y respecto de la continuación de nuestra especie, vinculando además nuestra generación con las siguientes en una trama social indispensable. El matrimonio irradia identidad, estabilidad y responsabilidad ético jurídica en la sociedad; contribuye al bien común, al bienestar social. Todavía hoy en la Argentina, en otros países y para muchas personas en el mundo, la familia fundada en el matrimonio es "el lugar al que se vuelve". ${ }^{12}$

Resulta evidente pues que este proyecto de ley carece de todo sustento fáctico, jurídico, lógico y racional; más aún si como sabemos tres son los requisitos que debe poseer la norma jurídica para que tenga la índole racional a causa de la prudencia:

10 Que sea conforme con la naturaleza humana (Conformidad con la moral y la justicia, esto es conformidad con la ley natural y el derecho)

2ㅇ Que esté acomodada al bien común

3o Que sea adecuada a la realidad social (Una norma no puede desordenar o desequilibrar una realidad social)

En tanto los derechos humanos son derechos naturales su respeto es parte de la más fundamental racionalidad de la norma jurídica. La racionalidad de la norma jurídica consiste en la conformidad de la norma con la naturaleza de las cosas. Actuar contra la naturaleza de las cosas, suele ser inútil las más de las veces, siempre es irracional por aberrante, contradictorio y arbitrario. ${ }^{13}$

Se señala además de que esta ley "busca introducir un régimen legal, completo y coherente para brindar tutela a las uniones afectivas estables. Tal régimen legal ha de ser similar en todo al existente para las uniones de hecho". Como puede pretenderse introducir un régimen legal y coherente si se está transgrediendo derechos constitucionales fundamentales y

\footnotetext{
${ }^{12}$ ARIAS DE RONCHIETTO, Catalina Elsa. Op. cit. p. 15

13 HERVADA, Javier. Lecciones Propedéuticas de Filosofía del Derecho, tercera edición, EUNSA, Pamplona, 1992, página 357.

${ }^{14}$ Cfr. CALIENES BEDOYA, Hugo. Op. cit. p. A2.
}

atentando contra el valor universal justicia que implica precisamente, dar a cada quien lo que realmente le corresponde.

Cuando un gobierno legisla lo hace para salvaguardar un derecho que está en peligro de ser vulnerado, nunca para congraciarse con determinados sectores .Toda protección por parte del Estado se fundamenta en el derecho natural, no es una dádiva para nadie, es el estricto cumplimiento de un deber. Por muchas leyes que se den el hombre seguirá siendo hombre y la mujer, mujer y la complementariedad entre ambos una realidad innegable desde cualquier punto de vista. El camino no es otorgar leyes benévolas que concedan derechos y homologuen estas uniones con la unión de la que nace la familia, célula vital de la sociedad, sino poner los medios para reencauzar inclinaciones de los confundidos y desde el Estado medidas preventivas con una política de salud sexual que respete la dignidad de la persona humana y no el error de querer convertir la excepción en ley general ${ }^{14}$ No le está dado al legislador poder alguno para cambiar el orden natural de las cosas ni la propia naturaleza humana. Su deber es legislar atendiendo a este orden natural por ello no debería haber incompatibilidad alguna entre la ley natural y la ley positiva pues ésta debería darse en función a la primera. Dado que todo aquello que vaya contra natura siempre va a lesionar y causar un daño al ser humano en los diferentes ámbitos de su vida, ya sea en su integridad física, psicológica, social, etc.

Como puede evidenciarse, las parejas homosexuales han emprendido una decidida guerra por ser reconocidos como titulares de derechos de orden familiar, algo que como se ha analizado y verificado, no les corresponde y como ellos mismos han señalado esto constituiría el primer paso o la puerta de ingreso para conseguir su fin último el cual es conseguir que se permita la celebración del acto jurídico del matrimonio entre personas del mismo sexo.

"Todo esto tiene como fundamento filosófico último el rechazo frontal de la existencia de una naturaleza humana y de una cierta naturaleza de la familia, que condicionan los contenidos de su regulación jurídico-social e imponen vallas morales infranqueables a la arbitrariedad de los individuos y - sobre todo- a la voluntad de poder enmascarada esta vez con el sutil disfraz del colectivismo permisivo" 15

Está prohibido todo aquello que atente contra el orden público, la moral y las buenas costumbres; así el Art. $V$ del Título Preliminar del Código Civil establece que es nulo el acto jurídico contrario a las leyes que interesan al orden público o a las buenas costumbres. Todo esto va en detrimento de la paz social, del orden, la moral pública y las buenas costumbres. Atropello sufrido por instituciones centrales de nuestra cultura y sociedad como lo es la familia fundada en el matrimonio y la relación varón-mujer.

"El trato homosexual no constituye matrimonio ni es apto para fundar una familia. Reconocemos la dignidad de las personas que practican la homosexualidad, por serlo; pero

15 MASSINI CORREAS, Carlos Ignacio. "La filosofía de los derechos humanos y la regulación jurídica de la familia", en El Derecho, no7635, 10 de Diciembre de 1990.citado por ARIAS DE RONCHIETTO, Catalina Elsa. Op. cit. p. 18. 
ello no implica admitir la equiparación de la homosexualidad con la heterosexualidad. Además, se sabe que asumen esta práctica sexual -no la denomino condición- de diversos modos y grados, pero su pretensión de ser reconocidos como formas de familia constituye un abuso arbitrario, al que no calificamos de abuso de derecho, porque no existe ni puede fundarse objetivamente un derecho a dar origen a una familia a partir de dos personas homosexuales. En cambio, lógicamente, una persona homosexual integra y es titular de todos los derechos, deberes, impedimentos, y obligaciones correspondientes a su familia de origen: En ella con todo derecho es hijo, hermano, nieto, tío, primo, sobrino. Pero no puede contraer matrimonio, ni fundar una familia". ${ }^{16}$

"Respecto a las parejas homosexuales, el único fundamento posible de reconocimiento jurídico es el deseo psicológico de los convivientes .Pero ya sabemos que ese deseo no justifica el reconocimiento y la protección de la sociedad a través del Derecho ( como tampoco justificaría el reconocimiento y la protección jurídica, mediante un régimen normativo específico, de la amistad) La afectividad, en sí y por sí, no interesa al Derecho; y la sexualidad básicamente en relación con sus consecuencias ( la procreación), pero entonces con gran intensidad e institucionalmente. La unión homosexual es un caso de relación afectiva con contenido sexual, pero sin consecuencias sociales relevantes derivadas de su propia naturaleza. Desde este punto de vista, no interesa a la sociedad, ni tampoco al Derecho. Es más, el interés estaría, en todo caso, en desincentivarlas, por su evidente disfuncionalidad"17

La unión entre hombre y mujer tiene unas características estructurales y funcionales que la diferencian de la unión entre dos hombres o dos mujeres; que esas diferencias son lo bastante relevantes como para justificar denominaciones distintas que permitan identificarlas y un tratamiento jurídico diferenciado; y que ambas cosas, en sí mismas, no suponen una consideración peyorativa de las uniones homosexuales. Los nuevos ciudadanos que aseguran la continuidad social, proceden de uniones entre personas de distinto sexo, no de uniones homosexuales: la trascendencia social de uno y otro fenómeno es, pues, bien distinta, y el interés de la sociedad en uno u otro tipo de uniones es también diferente.

Las uniones entre personas del mismo sexo son muchísimo más inestables que los matrimonios. Los índices de fidelidad a su pareja son muy superiores entre los cónyuges heterosexuales que (en torno al $80 \%$ ), que entre los varones homosexuales (en torno al 5\%)

Las diferencias de denominación y de régimen jurídico no son arbitrarias, sino que responden al hecho de que se trata de dos fenómenos bien distintos, en su estructura, en sus consecuencias, y en la dinámica a que responde su relación. ${ }^{18}$

\section{Conclusiones}

El proyecto de ley № 04181/2010-CR resulta inviable por ser manifiestamente inconstitucional, conforme se ha sustentado en los fundamentos jurídicos expuestos.

Es incontrastable que para la Constitución y las leyes peruanas el matrimonio y el concubinato solo puede darse entre varón y mujer, no así entre personas del mismo sexo. El proyecto de ley № 04181/2010-CR el mismo que propone establecer las uniones civiles entre personas del mismo sexo no pasa el test de proporcionalidad o razonabilidad, principio orientador de todo el sistema jurídico.

\footnotetext{
${ }^{16}$ ARIAS DE RONCHIETTO, Catalina Elsa. Op. cit. p. 15.

${ }^{17}$ MARTÍNEZ DE AGUIRRE ALDAZ, Carlos. Diagnóstico sobre el derecho de familia. Análisis sobre el sentido y los contrasentidos de las transformaciones contemporáneas del Derecho de Familia. Documentos del instituto de Ciencias para la familia. Universidad de Navarra, Ediciones Rialp, S.A., España, 1996, p. 168.
}

${ }^{18}$ Cfr. MARTínEZ dE AGUIRRE ALDAZ, Carlos y DE PABLO CONTRERAS, Pedro. Op. cit. p.44. 